\title{
Scandinavian Design: Alternative Histories
}

Edited by Kjetil Fallan. Berg 2012.

by Maija Mäkikalli

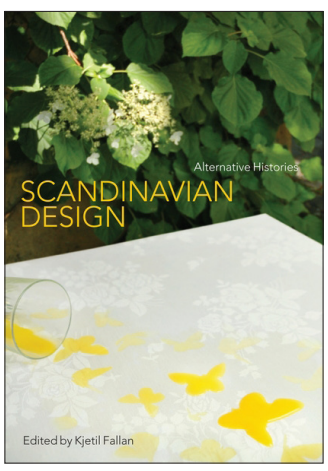

Kjetil Fallan has edited a refreshing book called Scandinavian Design: Alternative histories which can be read at least from two perspectives. The book introduces new histories of design in Scandinavia and - as the subtitle points out - offers alternatives to the well-known histories we have read earlier. This history of Scandinavian design is described as a "cleverly crafted concept [which] has led to a disturbingly narrow understanding of Nordic design culture"[p. 1.], meaning characterizations such as "'humane', 'democratic', 'organic' and 'blond'." [p. 4.]. Indeed, the case studies presented in this new book of diverse topics such as the changes of copyright legislation in Denmark, the design process of reverse wending machines in Norway, the Cooperative Union's consumer policy and its "nonbranded" products in Sweden, or design students' political activity in the 1970s Finland have not been part of the earlier narratives on the history of Scandinavian design available in English. According to Fallan, such themes have been 'marginalised' in the previous accounts. [p. 1.] Thus the book opens a wider field of 'Nordic design culture' beyond the narrow conceptions of Scandinavian design and its history to its international readers.

This collection can also be read as introducing topical ways of doing design history - in any regional location. The book is divided into three parts corresponding to three concepts: networks, appropriations and mediations, each of which provides a focus or a tool for analyzing design, how it is, how it has been, or how it works. Indeed, in his introduction Fallan not only defines and contextualizes the concept of Scandinavian design and reasons why alternative histories are needed, he also deals with current design history writing in general, and the structuring concepts of the book help to highlight its contributions to "contemporary developments in design history's theory and method." [p. 7.] As much as the structuring concepts are linked to the case studies themselves, they also refer to the intersection of disciplines this book derives from, such as history of technology, design history or cultural history.

At times the reader may wonder whether a case study in question really benefits from the shared concept of the part or not. On the other hand, Fallan's way of finding shared concepts among these case studies, and structuring the collection accordingly, gives the reader useful material to consider while reading the individual studies with their own methodological choices. Yet another question is whether these alternative histories could have been structured with other concepts, such as 'otherness', or 'alternative moderns', and what results those would have produced with regard to the narrow conceptions of Scandinavian design that the book wants to criticize. In the last chapter of the book, "Epilogue", Fallan suggests tasks for future studies. He points out that gender, class and race (or ethnicity) are categories which still are under-explored in the field of design history in Scandinavia. To some extent these concepts are already in use in the case studies of this book - even if not explicitly so. Class, for instance, makes a good conceptual pair for democracy in deconstructing the narratives of Swedish design history, as we can see in Christina Zetterberg's analysis of Wilhelm Kåge's Liljeblå dinnerware and its subjects.

A crucial reason for the limited understanding of the history of design in Scandinavia among the international readership is the availability and access to the research literature of the topic. A 'Historiography' on design history literature in Scandinavia ('PanScandinavian literature'), Sweden, Norway, Denmark and Finland is a valuable chapter for English-reading students and scholars. This chapter also serves one of the aims of this book: it wants to, and without a question also does, refresh and generate new studies of Scandinavian design history. To Scandinavian scholars this chapter is a reminder of the importance of publishing one's work in English. Fallan also reminds the reader that Norway and Denmark still don't have national survey histories of design. The lack of research literature, written in English, by Scandinavian or Nordic scholars is something that this book corrects. Thus, together with Malene Breunig, Hans-Christian Jensen, Anders V. Munch and Stina Teilmann-Lock from Denmark, Pekka Korvenmaa, Minna Sarantola-Weiss and Leena Svinhufvud from Finland, Espen Johnsen, Stig Kvaal and Per Østby from Norway, Finn Arne Jørgensen from Norway and Sweden, Sara Kristoffersson, Helena Mattsson, Jeff Werner and Christina Zetterlund from Sweden, Fallan succeeds in producing a body of work that brings Scandinavian research to the forefront.

If the structure of the book is rewarding, so are the individual chapters. They offer highly interesting readings of design historical studies in four Scandinavian countries. The earliest cases are from the beginning of the twentieth-century, and the latest from our own time; however, most of the contributors study the period from the 1920 s to the 1970s. The cases deal with a wide variety of designed products, processes or related matters: dinnerware, photographs, brands, chocolate bars, trams, textile design production, sofas, legislation or political activity. They all widen our understanding of both design and design related contexts in Scandinavia, and the ways those can be explored. Kjetil Fallan has produced a highly recommended work in editing these contributions for readers both in academia and beyond, both in Scandinavia and outside.

Maija Mäkikalli is Lecturer in art and cultural history at the University of Lapland. She specialises in the history of design and material culture. 